\title{
Exploring the Beliefs of Primary Education Teachers Regarding the Contribution of Mentoring in Schools
}

\author{
Dr. Niki Phillips \\ Tutor, Hellenic Open University \\ Head of Human Resource Development, Bank of Cyprus, Greece \\ Sokratous 18, Kastelokampos, Rio, zc. 26504, Patra- Greece \\ Tel: 30-694-568-1885 E-mail: nphillip@bankofcyprus.gr \\ Dr. Iosif Fragoulis \\ As. Professor, School of Pedagogical and Technological Education \\ Tutor, Hellenic Open University \\ Sokratous 18, Kastelokampos, Rio, zc. 26504, Patra- Greece \\ Tel: 30-261-091-0066 E-mail: sfaka@otenet.gr
}

\begin{abstract}
This paper examines the impact of mentoring in primary education. The research undertaken with primary education teachers working in schools of the Achaia Region, (Greece), analyses their beliefs and attitudes towards the implementation of mentoring and the relation of these attitudes with demographic data.

Theories regarding the meaning, process, techniques and benefits of mentoring are explored in the first part in order to explain the impact of a mentor in a school environment. The second part presents and interprets the data collected and detects the relation between teachers' attitudes and demographic data.
\end{abstract}

Keywords: Mentoring, Mentee, Primary education, Teacher's beliefs

\section{DEFINING MENTORING}

The modern (Note 1) use of the word mentor is "a trusted friend, counselor or teacher" (Cunningham \& Eberle 1993. Kefalas, 2005:2. Equal, 2006: 22). Mentoring finds its original meaning in a reference to a relationship between two people, one older with greater experience (the mentor), the other, usually younger, with less experience (the mentee, or as most American authors prefer: the protégé) (Friday \& Friday, 2002:154). The core of the relationship is that it is development-oriented, and also embedded in the setting of a "career" (Westlander, 2009:82).

Nowadays mentors provide expertise to less experienced individuals to help them advance their careers, enhance their education, and build their networks, thus in many different arenas people have benefited from being part of a mentoring relationship (Papastamatis, 2010:210).

In the organizational setting, mentoring can take many forms. One definition of the many that has been proposed, is "Mentoring is a process for the informal transmission of knowledge, social capital, and the psychosocial support perceived by the recipient as relevant to work, career, or professional development; mentoring entails informal communication, usually face-to-face and during a sustained period of time, between a person who is perceived to have greater relevant knowledge, wisdom, or experience (the mentor) and a person who is perceived to have less (the protégé)" (Bozeman \& Feeney 2007: 317).

Today, mentoring is a one-to-one interaction model that organizations can exploit in order to develop their people, and an important approach very much in harmony with the lifelong learning philosophy of adult and continuing education (Cohen \& Galbraith, 1995: 5). It can be an informal practice or a formal program. Mentees, observe, question, and explore. Mentors demonstrate, explain and model. 


\section{MENTORING TECHNIQUES}

Mentoring is a one-to-one interactive process of guided developmental learning based on the premise that the participants will have reasonably frequent contact and sufficient interactive time together. Mentors contribute their knowledge, proficiency, and experience to assist mentees who are workhng toward the achievement of therir own objectives. As the realtionship evolves, mentees usually interpret the collaborative learning experiecne with and from their mentors as increasingly importan to them (Cohen \&Galbraith, 1995:5).

Since the focus of mentoring is to develop the whole person, the techniques are broad and require wisdom in order to be used appropriately. A study of mentoring techniques most commonly used in business reveals five major "wisdom tactics" mentors usually follow. These are:

1. Accompanying: This means making a commitment in a caring way. Accompanying involves taking part in the learning process by taking the path with the learner.

2. Sowing: Mentors are often confronted with the difficulty of preparing the learner before he or she is ready to change. Sowing is necessary when you know that what you say may not be understood or even acceptable to learners at first but will make sense and have value to the mentee when the situation requires it.

3. Catalyzing: When change reaches a critical level of pressure, learning can jump. Here the mentor chooses to plunge the learner right into change, provoking a different way of thinking, a change in identity or a re-ordering of values.

4. Showing: this is making something understandable, or using your own example to demonstrate a skill or activity. You show what you are talking about, you show by your own behavior.

5. Harvesting: Here the mentor focuses on "picking the ripe fruit": it is usually learned to create awareness of what was learned by experience and to draw conclusions. The key questions here are: "What have you learned?" "How useful is it?"

Different techniques may be used by mentors according to the situation and the psychological mindset of the mentee. It is underlined that the techniques used in modern organizations can be found in ancient education systems, from the Socratic technique of harvesting to the accompaniment method of learning used in the apprenticeship of itinerant cathedral builders during the Middle Ages (Bob \& Cohen, 1995:23 on: http://en.wikipedia.org/wiki/Mentoring, 2010:1).

\section{QUALITIES OF THE MENTOR}

As a highly significant influence, the competent mentor demonstrates skills by effectively interacting with the mentee to support and advance learning, whether that learning is associated with educational or career goals (Cohen \& Galbraith, 1995:6). In their exploration of the mentoring mindset Millwater and Yarrow (Cox, 2003:14), confirm that mentors' approaches to mentoring can differ depending upon their own particular experiences of education and support, and that an exploration of the nature of knowledge held by mentors is important.

However, the basic qualities which seem to be essential for a mentor's role, and are used to asses his/her potential effectiveness, are the following (Conway, 1995:6. Finlay-Clifford \& Green, 1996:80):

- A desire to help: Individuals who are interested in and willing to help others.

- Have had positive experiences: Individuals who have had positive formal or informal experiences with a mentor tend to be good mentors themselves.

- Good reputation for developing others: Experienced people who have a good reputation for helping others develop their skills.

- Time and energy: People who have the time and mental energy to devote the relationship.

- Up-to-date knowledge: Individuals who have maintained current, up-to-date technological knowledge and / or skills.

- Learning attitude: Individuals who are still willing and able to learn and who see the potential benefits of a mentoring relationship.

- Demonstrated effective managerial (mentoring) skills: Individuals who have demonstrated effective coaching, counseling, facilitating and networking skills. 


\section{QUALITIES OF THE MENTEE}

The essential characteristics Mentees should have in order to successfully develop through the mentoring process are:

- $\quad$ Committed to expanding their capabilities

- $\quad$ Open and receptive to new ways of learning and trying new ideas

- $\quad$ Able to accept feedback and act upon it

- Willingness to apply leanings back on the job

- $\quad$ Focused on achieving desired business results

- $\quad$ Able to communicate and work cooperatively with others

- Know when to ask for help

- Have a sense of personal responsibility and commitment

- Willing to meet with the mentor on a regular basis

www.sonic.net./ mfreeman/mentor/protchar.htm, 2010:1)

\section{MENTORING BENEFITS}

Research in the mentoring literature demonstrates that all concerned parties gain from participating in mentoring relationships: mentors, mentees, and organizations. Mentoring offers adult learners opportunities for significant personal, academic and career development. It is a pragmatic approach that helps Mentees to successfully navigate the complex and rapid social and economic transitions that characterize our century (Cohen \& Galbraith, M., 1995:5).

\section{Benefits to Mentor:}

- Creates opportunities for experienced professionals to strengthen their knowledge base and improve communication skills.

- Enhances the leadership, teaching, and coaching skills of mentors and encourages them to become more reflective practitioners.

- $\quad$ Creates new support networks with other professionals in the field and promotes greater collegiality among professionals within and across institutions.

- $\quad$ Provides intrinsic satisfaction (makes you feel good) by helping an emerging professional develop to his/her potential.

- Demonstrates professionalism and a commitment to personal and professional development of self and colleagues.

- $\quad$ Promotes the professional recognition of mentors for their commitment to developing the talents of new professionals.

\section{Benefits to Mentee:}

- $\quad$ Promotes a professional relationship that fosters guidance and support during the mentee's development.

- May increase the self-confidence of a new professional as he/she becomes familiar with a new role, increased responsibilities, or a new organizational culture.

- Challenges mentees to go further, take risks, set new goals, and achieve at higher personal and/or professional standards.

- $\quad$ Provides a forum to dialogue on professional issues and to seek and receive advice on how to balance new responsibilities.

- Matches a new professional with an experienced professional in the field and promotes networking and visibility.

- $\quad$ Provides role modelling for professional leadership and facilitates the development of increased competencies and stronger interpersonal skills.

- $\quad$ Reflects the mentee's commitment to personal and professional growth.

Benefits to Organizations: 
1. Contributes to a positive organizational climate and promotes a more clear understanding of professional responsibilities and expectations.

2. May increase employee satisfaction and retention by reducing a new employee's sense of isolation.

3. May result in improved employee job performance, contribute to faster learning curves, and result in a better trained staff.

4. Reflects an investment in employee development and may increase employee commitment and loyalty.

5. Promotes a positive image of the organization and reflects employee-centred values.

6. Contributes to the development of partnerships or allies that may be useful to the organization in the future

7. Effective mentoring can be one of the best tools for building diversity.

www.coe.uga.edu/chds/mentoring/benefits.htm, 2010:1)

\section{MENTORING AND THE EDUCATIONAL SYSTEM}

Mentoring has considerable importance as a means of strengthening the general educational system. Given the difficult issues confronted by the often overburdened educators in the public school system, the mentor-mentee approach offers important assistance in the critical effort to increase student retention and promote educational achievement.

Students with personal motivation difficulties, academic skills deficiencies or age-inappropriate behavioral problems can benefit from a close connection with mature adults. In addition, students who are demonstrating commitment to their education can engage in mentoring as means to enrich and advance their current learning pursuits.

In postsecondary education, mentoring is used as a direct intervention to support the continuing development of adult learners. Especially for those students from disadvantaged of nontraditional backgrounds, the mentoring relationship offers a significant survival bridge into and through what is to them the often very different world of academia. Faculty and staff mentors with "school-smart" knowledge and strategies serve as valuable resources for adult learners with few or no peer reference points to help them maneuver through and succeed in the college environment (Cohen \& Galbraith, 1995: 7-8).

Calabrese and Tucker-Ladd (1991) (Hausman,et al,2002:141) point out that mentoring was explored as a tool for strengthening the team leadership practice, and school principals have a strong responsibility to serve as mentors for the assistant principal. They consider the relationship between them as a social contract that benefits individuals on many levels.

\section{RESEARCH METHODOLOGY}

\subsection{Purpose}

The exploration of primary teachers' beliefs and attitudes in relation to the effectiveness of the mentoring process in the school environment is this study's main purpose.

\subsection{Research questions}

1. Are teachers' beliefs - regarding benefits from participation in the mentoring process - relevant to demographic characteristics?

2. Are teachers' beliefs - regarding the mentor's benefits from participation in the mentoring process relevant to demographic characteristics?

3. Are teachers' beliefs - regarding mentoring impact on improvement of communication amongst individuals in a school unit - relevant to demographic characteristics?

4. Are teachers' beliefs - regarding mentoring impact on improvement of the education quality offered by the school unit - relevant to demographic characteristics?

\subsection{The sample}

The research sample consisted of 120 teachers (Note 2) of various expertise (teachers specialized in general primary school tuition, English language teachers, French language teachers, Physical education teachers, Music teachers, etc). 


\subsection{Data Collection}

The questionnaire was chosen as the data collection tool, since it allows the gathering of multitude information in a short period of time. The large number of schools operating in the Achaia Region, combined with the researchers' limited time and availability of transportation, made it difficult to apply any other collection methods (Kvale, 1996:104. Dimitropoulos, 2001: 210. Robson, 2002:271).

\subsection{Data Analysis}

The answers collected by the questionnaire were analyzed by SPSS V. 17, a widely used statistical analysis programme in the Social Sciences field.

\section{FINDINGS}

\subsection{Demographic characteristics}

The research sample's distribution in relation to demographic characteristics is as follows:

\section{Gender:}

76 members $(61,3 \%)$ was male teachers and 48 members $(38,7 \%)$ was female teachers.

Age:

$24(20,0 \%)$ teachers belong to the age group of 25-34

$72(60,0 \%)$ teachers belong to the age group of $35-44$

$24(20,0 \%)$ teachers belong to the age group of $45-54$

\section{Insert Table 1 Here}

\section{Expertise:}

$72(60,0 \%)$ teachers are involved in general primary school education,

$10(8,3 \%)$ are English language teachers,

$18(15,0 \%)$ are Physical Education teachers,

$12(10,0 \%)$ are Music teachers, and

$8(6,7 \%)$ are French language teachers.

\section{Insert Table 2 Here}

\section{Years of experience in Education:}

$36(30,0 \%)$ teachers have between 1-10 years of experience,

$48(40,0 \%)$ teachers have between 11-20 years of experience and

$36(30,0)$ teachers have between 21-30 years of experience.

\section{Years employed in current school:}

$12(10,0 \%)$ teachers have been employed in the current school for the last 1-5 years,

$60(50,0 \%)$ teachers have been employed in the current school for the last $6-10$ years, and $48(40,0 \%)$ teachers have been employed in current school for the last 11-15 years.

\section{Professional status:}

$69(57,5 \%)$ individuals are teachers,

$25(20,8 \%)$ individuals are assistant managers and

$26(21,7 \%)$ individuals are Head Masters.

\section{Insert Table 3 Here}

\section{Post graduated credentials and other professional qualifications:}

$68(56,7 \%)$ individuals quoted that they have attended an annual training programme implemented by the Schools of Primary Teachers Vocational Training. 24 individuals $(20,0 \%)$ quoted that they have a masters degree in education and 28 members $(23,3 \%)$ quoted that they have attended various training programmes of over 300 hours in duration. 


\subsection{Subjects' beliefs regarding teachers' benefits from participation in the mentoring process}

The single-variable analysis of the subjects' beliefs to the question "Does your participation in mentoring processes contribute to the provision of learning opportunities in a non threatening environment" showed that:

85 individuals (70, $8 \%$ ) answered: Immensely

21 individuals $(17,5 \%)$ answered: Considerably

14 individuals (11,7\%) answered: Sufficiently and Remotely

The bivariable analysis of subject answers, using the chi-square criteria, showed statistically important differences $(\alpha<0,05)$, in relation to variables such as gender $(\mathrm{p}=0,000)$, age $(\mathrm{p}=0,001)$ and years of experience $(\mathrm{p}=0,002)$.

\section{Insert Table 4 Here}

The single-variable analysis of the subjects' beliefs to the question "Does your participation in mentoring processes contribute to the development of self-confidence regarding implementation of your teaching practices" showed that:

21 individuals (17, $5 \%$ ) answered: Immensely

83 individuals $(69,2 \%)$ answered: Considerably

16 individuals (13,3\%) answered: Sufficiently and Remotely

The bivariable analysis of subject answers, using the chi-square criteria, showed statistically important differences $(\alpha<0,05)$, in relation to variables such as gender $(p=0,000)$, field of expertise $(p=0,01)$ and training $(\mathrm{p}=0,002)$.

The single-variable analysis of the subjects' beliefs to the question "Does your participation in mentoring processes contribute to the acquisition of experiences and expertise" showed that:

45 individuals (37, $5 \%$ ) answered: Immensely

46 individuals $(38,3 \%)$ answered: Considerably

29 individuals (24,2\%) answered: Sufficiently and Remotely

The bivariable analysis of subject answers, using the chi-square criteria, showed statistically important differences $(\alpha<0,05)$, in relation to variables such as field of expertise $(\mathrm{p}=0,01)$, years of experience in education $(\mathrm{p}=0,001)$ and years of employment in current school $(\mathrm{p}=0,002)$.

The single-variable analysis of the subjects' beliefs to the question "Does your participation in mentoring processes contribute to effective problem solving within the school environment" showed that:

45 individuals (37, $5 \%$ ) answered: Immensely

46 individuals $(38,3 \%)$ answered: Considerably

29 individuals (24,2\%) answered: Sufficiently and Remotely

\section{Insert Table 5 Here}

The single-variable analysis of the subjects' beliefs to the question "Does your participation in mentoring processes contribute to the development of professional networking and teamwork" showed that:

22 individuals (18, $3 \%)$ answered: Immensely

71 individuals $(59,2 \%)$ answered: Considerably

27 individuals (22,5\%) answered: Sufficiently and Remotely

The bivariable analysis of subject answers, using the chi-square criteria, showed statistically important differences $(\alpha<0,05)$, in relation to variables such as field of expertise $(p=0,01)$, years of experience in education $(\mathrm{p}=0,001)$, years of employment in current school $(\mathrm{p}=0,002)$ and post graduate studies $(\mathrm{p}=0,001)$.

The single-variable analysis of the subjects' beliefs to the question "Does your participation in mentoring processes contribute to the development of a coaching system by an experienced employee in the education field" showed that:

66 individuals (55, $0 \%)$ answered: Immensely

47 individuals $(39,2 \%)$ answered: Considerably 
7 individuals (5, 8\%) answered: Remotely

The bivariable analysis of subject answers, using the chi-square criteria, showed statistically important differences $(\alpha<0,05)$, in relation to variables such as field of expertise $(\mathrm{p}=0,00)$, years of experience in education $(\mathrm{p}=0,000)$ and years of employment in current school $(\mathrm{p}=0,000)$.

\section{Insert Table 6 Here}

\subsection{Subjects' beliefs regarding mentor's benefits from participation in the mentoring process}

The single-variable analysis of the subjects' beliefs to the question "Does a mentor develop his/her communication skills through participation in the mentoring process" showed that:

44 individuals (36, 7 \%) answered: Immensely

47 individuals (39, 2\%) answered: Considerably

29 individuals $(24,1 \%)$ answered: Sufficiently and Remotely

The single-variable analysis of the subjects' beliefs to the question "Does a mentor develop his/her cooperation skills through participation in the mentoring process" showed that:

61 individuals (50, $8 \%$ ) answered: Immensely

48 individuals $(40,0 \%)$ answered: Considerably

11 individuals $(9,2 \%)$ answered: Sufficiently and Remotely

The bivariable analysis of subject answers, using the chi-square criteria, showed statistically important differences $(\alpha<0,05)$, in relation to variables such as gender $(p=0,000)$, expertise $(p=0,000)$, years of experience in education $(\mathrm{p}=0,000)$ and training $(\mathrm{p}=0,001)$.

\section{Insert Table 7 Here}

The single-variable analysis of the subjects' beliefs to the question "Does a mentor provide support to new teachers with little experience, through the mentoring process" showed that:

48 individuals (40, $0 \%$ ) answered: Immensely

71 individuals $(59,2 \%)$ answered: Considerably

1 individual $(0,8 \%)$ answered: Sufficiently

The bivariable analysis of subject answers, using the chi-square criteria, showed statistically important differences $(\alpha<0,05)$, in relation to variables such as gender $(p=0,001)$, expertise $(p=0,01)$, years of experience in current school $(\mathrm{p}=0,001)$ and training $(\mathrm{p}=0,000)$.

The single-variable analysis of the subjects' beliefs to the question "Does a mentor feel increased job satisfaction through participation in the mentoring process" showed that:

45 individuals (37, $5 \%$ ) answered: Immensely

72 individuals $(60,0 \%)$ answered: Considerably

3 individuals (2, 5\%) answered: Sufficiently \& Remotely

\section{Insert Table 8 Here}

The single-variable analysis of the subjects' beliefs to the question "Does a mentor feel increased job contribution through participation in the mentoring process" showed that:

68 individuals (56, $7 \%$ ) answered: Immensely

24 individuals $(20,0 \%)$ answered: Considerably

28 individuals $(23,3 \%)$ answered: Sufficiently

The bivariable analysis of subject answers, using the chi-square criteria, showed statistically important differences $(\alpha<0,05)$, in relation to variables such as gender $(p=0,001)$, expertise $(p=0,01)$, years of experience in education $(\mathrm{p}=0,001)$.

The single-variable analysis of the subjects' beliefs to the question "Does a mentor develop his/her critical reflection upon training techniques and methods applied in mentoring, through participation in the mentoring process" showed that:

41 Individuals $(34,2 \%)$ answered: Immensely 
48 individuals $(40,0 \%)$ answered: Considerably

28 individuals $(23,3 \%)$ answered: Sufficiently

3 individuals (2, 5\%) answered: Remotely

\section{Insert Table 9 Here}

8.4 Subjects' beliefs regarding mentor's contribution to communication improvement_within the school environment

The single-variable analysis of the subjects' beliefs to the question "Are school operation objectives achieved due to mentoring implementation" showed that:

69 individuals (57, $5 \%$ ) answered: Immensely

48 individuals (40, $0 \%)$ answered: Considerably

3 individuals (2, 5\%) answered: Sufficiently

The bivariable analysis of subject answers, using the chi-square criteria, showed statistically important differences $(\alpha<0,05)$, in relation to variables such as gender $(p=0,000)$, expertise $(p=0,01)$, years of employment in school $(\mathrm{p}=0,001)$.

The single-variable analysis of the subjects' beliefs to the question "Does mentoring develop communication and cooperation skills amongst teachers" showed that:

69 individuals (57, $5 \%$ ) answered: Immensely

24 individuals (20,0\%) answered: Considerably

2 individuals $(22,5 \%)$ answered: Sufficiently

\section{Insert Table 10 Here}

The single-variable analysis of the subjects' beliefs to the question "Does mentoring develop communication and cooperation skills between teachers and the Head Master" showed that:

71 individuals (59, $1 \%$ ) answered: Immensely

47 individuals $(39,2 \%)$ answered: Considerably

2 individuals (1,7\%) answered: Sufficiently

The bivariable analysis of subject answers, using the chi-square criteria, showed statistically important differences $(\alpha<0,05)$, in relation to variables such as gender $(\mathrm{p}=0,000)$, expertise $(\mathrm{p}=0,01)$, years of experience in education $(\mathrm{p}=0,01)$ and years of employment in current school $(\mathrm{p}=0,001)$.

The single-variable analysis of the subjects' beliefs to the question "Does mentoring develop communication and cooperation skills between teachers and executive education administrative staff" showed that:

61 individuals (50, $8 \%$ ) answered: Immensely

48 individuals $(40,0 \%)$ answered: Considerably

11 individuals $(9,2 \%)$ answered: Sufficiently

The bivariable analysis of subject answers, using the chi-square criteria, showed statistically important differences $(\alpha<0,05)$, in relation to variables such as gender $(p=0,000)$, expertise $(p=0,01)$, years of experience in education $(\mathrm{p}=0,01)$.

The single-variable analysis of the subjects' beliefs to the question "Does mentoring enhance problem solving for matters arising in the school environment" showed that:

42 individuals (35, $0 \%)$ answered: Immensely

48 individuals $(40,0 \%)$ answered: Considerably

30 individuals $(23,3 \%)$ answered: Sufficiently

The bivariable analysis of subject answers, using the chi-square criteria, showed statistically important differences $(\alpha<0,05)$, in relation to variables such as gender $(\mathrm{p}=0,001)$, expertise $(\mathrm{p}=0,00)$, years of experience in current school $(\mathrm{p}=0,00)$.

\section{Insert Table 11 Here}


8.5 Subjects' beliefs regarding the contribution of mentoring to the quality improvement of the school's educational practices

The single-variable analysis of the subjects' beliefs to the question "Does mentoring improve the quality of the school's educational practices" showed that:

46 individuals (38, $4 \%$ ) answered: Immensely

72 individuals $(60,0 \%)$ answered: Considerably

2 individuals $(1,6 \%)$ answered: Sufficiently

The bivariable analysis of subject answers, using the chi-square criteria, showed statistically important differences $(\alpha<0,05)$, in relation to variables such as gender $(\mathrm{p}=0,001)$, expertise $(\mathrm{p}=0,00)$, years of experience in education $(\mathrm{p}=0,01)$ and years of employment in the school $(\mathrm{p}=0,000)$.

The single-variable analysis of the subjects' beliefs to the question "Does mentoring facilitate human resource management of the school's employees" showed that:

46 individuals (38, $4 \%$ ) answered: Immensely

72 individuals $(60,0 \%)$ answered: Considerably

2 individuals (1, 6\%) answered: Sufficiently

\section{Insert Table 12 Here}

The single-variable analysis of the subjects' beliefs to the question "Does mentoring contribute to the school's growth and development" showed that:

48 individuals (40, $0 \%$ ) answered: Immensely

72 individuals $(60,0 \%)$ answered: Considerably

The bivariable analysis of subject answers, using the chi-square criteria, showed statistically important differences $(\alpha<0,05)$, in relation to variables such as gender $(p=0,001)$, expertise $(p=0,00)$, years of experience in education $(\mathrm{p}=0,01)$ and years of employment in school $(\mathrm{p}=0,000)$.

The single-variable analysis of the subjects' beliefs to the question "Does mentoring reinforce innovation within the school environment" showed that:

46 individuals (38, $3 \%)$ answered: Immensely

47 individuals $(39,2 \%)$ answered: Considerably

27 individuals $(22,5 \%)$ answered: Sufficiently

\section{Insert Table 13 Here}

The single-variable analysis of the subjects' beliefs to the question "Does mentoring contribute to the school's internal reform" showed that:

45 individuals (37, $5 \%$ ) answered: Immensely

39 individuals $(32,5 \%)$ answered: Considerably

36 individuals (30,0\%) answered: Sufficiently

The bivariable analysis of subject answers, using the chi-square criteria, showed statistically important differences $(\alpha<0,05)$, in relation to variables such as gender $(p=0,00)$, expertise $(p=0,00)$, years of experience in education $(\mathrm{p}=0,01)$, years of employment in school $(\mathrm{p}=0,000)$ and teachers training $(\mathrm{p}=0,00)$.

\section{CONCLUSIONS}

The findings of this research show that a high percentage of the research subjects believe they benefit from the mentoring process. More specifically, they express the view that through mentoring they are provided with learning opportunities in a non-threatening environment, develop their self-confidence in relation to their teaching practices, and obtain important experiences and expertise. Additionally, their problem solving skills are empowered; they develop professional networking and teamwork skills and adopt a coaching method with the help of experienced training staff. These beliefs are highly influenced by the sample's demographic characteristics.

The findings of this research show that subjects also believe that mentors themselves greatly benefit from participation in the mentoring process. They express the opinion that mentors develop communication and 
teamwork skills as well as their supportive skills towards their colleagues. At the same time they receive job satisfaction, feel that they are highly contributing to their work and develop critical reflection skills. In these views one can detect the significant effect demographic characteristics have on teachers' beliefs regarding the mentors' benefits form their participation in the mentoring process.

This research also shows that the majority of subjects believe that mentoring in schools greatly contributes to the improvement of communication amongst their employees. More specifically they express the opinion that mentoring contributes to the achievement of the school's operational and educational aims, the development of equal relations and teamwork between teachers, as well as between them and the school's Head Masters. Furthermore, mentoring assists the cultivation of communication and teamwork between teachers and executive administrative employees and facilitates problem solving when issues arise in the school unit. In these views one can detect the significant effect demographic characteristics have on teachers' beliefs regarding the contribution of mentoring in the improvement of communication and teamwork.

Another conclusion accruing from the research findings is that a high percentage of subjects believe that mentoring contributes significantly to the improvement of the school's quality in regards to its educational practices. Specifically, they believe that through mentoring the training results as well as the management of human resources are improved. They also express the view that mentoring aids the school growth, supports innovation and launches internal reform. In these views one can detect the significant effect demographic characteristics have on teachers' beliefs regarding the contribution of mentoring in the improvement of the quality of the school's educational work

\section{RECOMMENDATIONS}

The systematic training of mentors on the mentoring process is a prerequisite for the effective implementation of mentoring in schools. Training should be carried out both with conventional training techniques (such as in-classroom training) and contemporary methods (such as distance learning courses). Such training should combine theory and practice.

In order to successfully design, organize and deliver a training programme on mentoring, a detailed training needs analysis of the participants should be carried out.

The contents of a mentoring training programme should include - apart from knowledge regarding mentoring techniques - the development of skills such as communication, teamwork, active listening, conflict management, empathy etc. Mentors should also practice control of their role's limits, so that mentoring will not end up a simple coaching process.

\section{References}

[Online] Available: http://en.wikipedia.org/wiki/Mentoring (31/03/2010).

[Online] Available: www.coe.uga.edu/chds/mentoring/benefits.htm (01/04/2010).

[Online] Available: www.sonic.net./ mfreeman/mentor/protchar.htm (16/03/2010).

Aubrey, B \& Cohen, P. (1995). Working Wisdom: Timeless Skills and Vanguard Strategies for Learning Organizations Jossey Bass, [Online] Available: http://en.wikipedia.org/wiki/Mentoring.

Bozeman, B \& Feeney, M. (2007). Toward a usefull theory of mentoring: A conceptual analysis and critique. Administration and Society, 39, 719-739.

Cohen, N., \& Galbraith, M. (1995). Mentoring in the Learning Society. Mentoring: New Strategies and Challenges, New Directions for Adult and Continuing Education, 66, 5-14, Jossey-Bass Inc.

Conway, C. (1995). Mentoring Managers in Organisations. Equal Opportunities International, 14, 1-52.

Cox, E. (2003). The Contextual Imperative: Implications for coaching and mentoring. International Journal of Evidence Based Coaching and Mentoring, 1, 9-22, Oxford Brookes University, UK.

Cunningham, J. \& Eberle, T. (1993). Characteristics of the Mentoring Experience: A Qualitative Study. Personnel Review, 22, 54-66.

Dimitropoulos, E. (2001). Introduction to the Methodology of scientific research. Athens: Ellin. (in Greek).

Equal. (2006). Development partnership "Telemachus" A study on Design and Delivery of Mentoring. Consulting Management Training. (in Greek).

Finlay-Clifford, E. \& Green, V. (1996). The Mentor-Protégé Relationship as a Factor in Preservice Teacher Education: A Review of the Literature. Early Child Development and Care, 125, 73-83. 
Friday, E. \& Friday, S. (2002). Formal mentoring: Is there a strategic fit? Management Decision, 40, 152-157.

Hausman, C., et al. (2002). The work life of the assistant principal. Journal of Educational Administration, 2, 136-157, Emerald Publishing.

Kefalas, A. (2005). The transition or succession procedure. [Online] Available: www.terry.uga.edu/ akefalas. (in Greek).

Kvale, S. (1996). Interviews: An Introduction to Qualitative Research Interviewing. London: Sage Publications.

Papastamatis, A. (2010). Adult Education for Vulnerable Social Groups. Thessalonica. (in Greek).

Robson, C. (2002). Real World Research. Oxford: Blackwell.

Westlander, G. (2009). (Book Review), Garvey, B., et al. (2009), Coaching and Mentoring. Theory and Practice. International Journal of Evidence Based Coaching and Mentoring, 7 (2), 82-96, Oxford Brookes University, UK.

\section{Notes}

Note 1. In Greek Mythology, Mentor was a trusted friend of Odysseus (a.k.a Ulysses). When Odysseus set out on his long wanderings knows as "odyssey", he left Mentor in charge of his palace and entrusted him the care and tutoring of his son Telemachus.

Note 2. Out of a total of 440 teachers employed in primary schools in the Achaia Region, Greece.

Table 1. Distribution in relation to Age

\begin{tabular}{|l|l|l|}
\hline $25-34$ age group & 24 & $20,0 \%$ \\
\hline $35-44$ age group & 72 & $60,0 \%$ \\
\hline $45-54$ age group & 24 & $20,0 \%$ \\
\hline TOTAL & 120 & $100 \%$ \\
\hline
\end{tabular}

Table 2. Distribution in relation to Field Specialization

\begin{tabular}{|l|l|l|}
\hline GENERAL PRIMARY SCHOOL EDUCATION & 72 & $60,0 \%$ \\
\hline ENGLISH LANGUAGE TEACHERS & 10 & $15,0 \%$ \\
\hline PHYSICAL EDUCATION TEACHERS & 18 & $15,0 \%$ \\
\hline MUSIC TEACHERS & 12 & $10,0 \%$ \\
\hline FRENCH LANGUAGE TEACHERS & 8 & $6,7 \%$ \\
\hline TOTAL & 120 & $100 \%$ \\
\hline
\end{tabular}

Table 3. Distribution in relation to Professional Status

\begin{tabular}{|l|l|l|}
\hline TEACHERS & 69 & $57,5 \%$ \\
\hline ASSISTANT MANAGERS & 25 & $20,8 \%$ \\
\hline HEAD MASTERS & 26 & $21,7 \%$ \\
\hline TOTAL & 120 & $100 \%$ \\
\hline
\end{tabular}


Table 4. Mentoring enhancing the provision of learning opportunities

\begin{tabular}{|l|l|l|}
\hline IMMENSELY & 85 & $70,8 \%$ \\
\hline CONSIDERABLY & 21 & $17,5 \%$ \\
\hline SUFFICIENTLY \& REMOTELY & 14 & $11,7 \%$ \\
\hline TOTAL & 120 & $100 \%$ \\
\hline
\end{tabular}

Table 5. Mentoring enhancing problem solving in the school environment

\begin{tabular}{|l|l|l|}
\hline IMMENSELY & 45 & $37,5 \%$ \\
\hline CONSIDERABLY & 46 & $38,3 \%$ \\
\hline SUFFICIENTLY \& REMOTELY & 29 & $24,2 \%$ \\
\hline TOTAL & 120 & $100 \%$ \\
\hline
\end{tabular}

Table 6. Mentoring and the development of a coaching system by An experienced employee

\begin{tabular}{|l|l|l|}
\hline IMMENSELY & 66 & $55,0 \%$ \\
\hline CONSIDERABLY & 47 & $39,2 \%$ \\
\hline REMOTELY & 7 & $5,8 \%$ \\
\hline TOTAL & 120 & $100 \%$ \\
\hline
\end{tabular}

Table 7. Mentoring developing cooperation skills

\begin{tabular}{|l|l|l|}
\hline IMMENSELY & 61 & $50,8 \%$ \\
\hline CONSIDERABLY & 48 & $40,0 \%$ \\
\hline SUFFICIENTLY \& REMOTELY & 11 & $9,2 \%$ \\
\hline TOTAL & 120 & $100 \%$ \\
\hline
\end{tabular}

Table 8. Mentoring enhancing Job satisfaction

\begin{tabular}{|l|l|l|}
\hline IMMENSELY & 45 & $37,5 \%$ \\
\hline CONSIDERABLY & 72 & $60,0 \%$ \\
\hline SUFFICIENTLY \& REMOTELY & 3 & $2,5 \%$ \\
\hline TOTAL & 120 & $100 \%$ \\
\hline
\end{tabular}

Table 9. Mentoring developing Critical reflection

\begin{tabular}{|l|l|l|}
\hline IMMENSELY & 41 & $34,2 \%$ \\
\hline CONSIDERABLY & 48 & $40,0 \%$ \\
\hline SUFFICIENTLY & 28 & $23,3 \%$ \\
\hline REMOTELY & 3 & $2,5 \%$ \\
\hline TOTAL & 120 & $100 \%$ \\
\hline
\end{tabular}


Table 10. Mentoring enhancing communication and cooperation skills development amongst teachers

\begin{tabular}{|l|l|l|}
\hline IMMENSELY & 69 & $57,5 \%$ \\
\hline CONSIDERABLY & 24 & $20,0 \%$ \\
\hline SUFFICIENTLY & 27 & $22,5 \%$ \\
\hline TOTAL & 120 & $100 \%$ \\
\hline
\end{tabular}

Table 11. Mentoring enhancing problem solving

\begin{tabular}{|l|l|l|}
\hline IMMENSELY & 42 & $35,0 \%$ \\
\hline CONSIDERABLY & 48 & $40,0 \%$ \\
\hline SUFFICIENTLY & 30 & $23,3 \%$ \\
\hline TOTAL & 120 & $100 \%$ \\
\hline
\end{tabular}

Table 12. Mentoring contribution to the management of the school's Human resources

\begin{tabular}{|l|l|l|}
\hline IMMENSELY & 46 & $38,4 \%$ \\
\hline CONSIDERABLY & 72 & $60,0 \%$ \\
\hline SUFFICIENTLY & 2 & $1,6 \%$ \\
\hline TOTAL & 120 & $100 \%$ \\
\hline
\end{tabular}

Table 13. Reinforcement of innovation due to mentoring

\begin{tabular}{|l|l|l|}
\hline IMMENSELY & 46 & $38,4 \%$ \\
\hline CONSIDERABLY & 47 & $39,2 \%$ \\
\hline SUFFICIENTLY & 27 & $22,5 \%$ \\
\hline TOTAL & 120 & $100 \%$ \\
\hline
\end{tabular}

